\title{
SOBRE LA HERENCIA ISLAMICA EN EL REGADIO VALENCIANO. Comentario a la obra de T.F. Glick «REGADIO Y SOCIEDAD EN LA VALENCIA MEDIEVAL» (Del Cenia al Segura, Valencia 1988)
}

\author{
Por \\ MATEO MARCO
}

En el año 1970 vió la luz la obra "Irrigation and Society in medieval Valencia» de Thomas F. Glick. Desde entonces este trabajo ha sido citado en todos los estudios sobre la Valencia medieval y, mucho más, en aquellos que han querido profundizar en los asuntos hidráulicos, económicos y sociales.

Después de dieciocho años, el libro de Glick ha sido traducido por Adela Almor. Así, todo lector español tiene, ahora, la posibilidad de penetrar, de la mano de un especialista, en el interesante mundo de la distribución, del reparto $y$ aprovechamiento del agua en tierras valencianas; por medio de un libro, de 413 páginas, cuidado en su encuadernación e imprenta de modo exquisito. Y hay que decir que entrar en el mundo del regadío valenciano de la mano de Glick es una garantía para no quedarse estancado en el fango. El conocimiento del autor queda demostrado, no sólo en esta amplia obra, sino también en sus múltiples artículos, donde ha analizado aspectos concretos de la sociedad e irrigación en Valencia como el de los niveladores, Tribunal de las Aguas, Abogados de Aguas, etc.

"Regadío y Sociedad en la Valencia Medieval» es una obra generosa, sobre todo porque presenta mucha documentación. No existen conclusiones, ni críticas, ni razonamientos que no estén avalados cientificamente con el peso de un documento histórico. Aun ante la falta de documentación escrita, por el carácter tantas veces consuetudinario de lo estudiado, Glick sabe encontrar lo preciso para dar sentido y confianza a sus teorías. Esto demuestra el dominio del tema por el autor, su saber y buen trabajo. También es generosa, 
la obra, porque estimula el deseo de estudiar los casos concretos que el autor conoce pero que, lógicamente por las características de generalidad del estudio, no están desarrollados en su plenitud.

Thomas F. Glick divide en dos partes el libro. En la primera, en siete capítulos, analiza las Comunidades Regantes de la Valencia Medieval; en la segunda parte, en seis capítulos, reflexiona sobre la continuidad cultural del regadio. Al final, añade un apéndice documental con textos y cuadros.

Es la primera parte un estudio general sobre la organización del regadío en Valencia. Click organiza con éxito este rompecabezas, lo resuelve. No es fácil entender los modelos medievales del uso del agua, las instituciones para el riego, las técnicas, las formas de colonización de las zonas regadas. Modelos, técnicas, instituciones, formas de colonización que se mantuvieron intactas hasta el sigio XIX cuando las innovaciones agrícolas modificaron algunos aspectos -subrayo algunos- de las huertas valencianas. No es fácil y no son pocos los que se han ahogado, los que se han atascado en el lodo cuando se han introducido en el terreno del regadío. Si las huertas con sus redes de acequias y campos regados fueron obstáculos defensivo en las guerras de conquista; conocer su organización es el primer impedimento que aparece hoy ante el estudioso que quiere conocer este imbricado mundo. Glick nos facilita el camino.

La compleja dinámica de las Comunidades de Regantes y de las unidades regionales de uso de agua es estudiada desde el conflicto social porque, según el autor, es en los registros de pleitos o litigios donde la dinámica de las Comunidades de Regantes medievales se hace más visible al historiador. La época más documentada es la que va desde 1238 a 1500. La ausencia de escritos se debe a que los juicios y sentencias eran orales. La maquinaria de la huerta exige un sistema judicial rápido para hacer efectivo el regadío de las tierras. También es necesaria una conciencia colectiva de que las responsabilidades son mutuas para la mayor eficacia. El cooperativismo es preciso en el regadío. Para cualquier modificación particular en la huerta se precisa la voluntad y consentimiento de la comunidad. Por ello, la Comunidad de Regantes aparece en Valencia como unidad básica para la distribución equitativa del agua $y$, por lo tanto, para evitar los conflictos entre usuarios. En Castellón, los sistemas de regadío están controlados por la municipalidad.

En definitiva, la primera parte de este estudio nos proporciona un claro conocimiento sobre la organización del regadío valenciano.

Para el lector interesado en los temas árabes, la segunda parte del libro de Glick es fundamental. En ella presenta, principalmente, el problema de los cambios culturales e institucionales durante la transición del poder islámico al cristiano en España. Comienza esta segunda parte en el capítulo VIII donde el autor realiza un análisis crítico de los estudios realizados sobre el regadío valenciano. El interés por el origen de los canales de riego, que si árabe o romano, ha sido y es una constante en la historiografía española. En la Edad 
Media, y de esto da constancia Glick, el sistema de regadío era reconocido como una herencia islámica. Sin embargo, en el siglo XVI la influencia islámica va a ser negada. En 1589, Ortiz de Mendoza atribuye un origen cristiano, anterior a los árabes, al sistema de riegos de Elche.

Posteriormente, la mayoría de los autores que en el siglo XIX escribieron sobre el regadío, estaban convencidos de su origen islámico. Borrull, Jaubert de Passa, Richard Ford, Markham, Aymard aunque más crítico, Pedro Díaz Cassou y Melchor Bellver y Vicente del Cacho defienden el origen islámico de la organización de los sistemas de riego hispanos. En el siglo XX se produce una bifurcación de las dos tradiciones historiográficas. Julián Ribera, a principios de siglo, decía que el sistema de regadío de la huerta valenciana «no es cosa de moros", y Wittfogel hablará de que con la dominación romana existe un regadío a pequeña escala y con pocas organizaciones institucionales mientras que con los árabes, se convierte en una genuina sociedad hidráulica. Glick desmenuza una por una las teorías con un gran espíritu crítico y científico para, en los siguientes capítulos, desarrollar su tesis.

En el capítulo IX establece un esquema cronológico sobre la evolución del regadío: primero, es el Próximo Oriente el foco de invención; segundo, el Imperio Romano hace una limitada difusión por el Mediterráneo; tercero, se intensifica el uso y el perfeccionamiento por los musulmanes del siglo VIII al $X$; cuarto, señala la especial intensidad de uso en al-Andalus; y quinto, alAndalus se convierte en foco difusor hacia el Norte de Africa y más tarde hacia América.

El autor defiende con argumentadas reflexiones que la organización del regadío en España es herencia de los árabes. Su origen concreto es, ciertamente, difícil de precisar y exige el análisis químico-arqueológico del mortero de las fábricas hidráulicas. En el capítulo X estudia la administración del regadío en al-Andalus, donde aparecen oficiales encargados del regadío que sobreviven en la época post-islámica. Es el caso del «qadi de las aguas» que ha dado el "alcalde de las aguas" (Lorca) o el del "Amin al-mâ", funcionario menor, que ha derivado, en valenciano, a Alamí y a Alamín, en castellano, o también en «fiel del agua» (Novelda, Elche) por traducción literal. Finalmente, tras presentar la distribución proporcional y medición del agua (capítulo XI) explica, en el capítulo XII, la impronta del Islam sobre la terminología del regadío. Los cristianos utilizaron la nomenclatura árabe. Glick enumera y disecciona palabras y topónimos de origen árabe relacionadas con el uso del agua. Muy interesante e instructivo este capítulo XII.

Tras las pruebas, en el último capítulo, establece una distinción de los sistemas de regadío en función de una discutible concepción de al-Andalus como mosaico de etnias - ¿acaso separadas?-. Así Glick, para justificar la no homogeneidad de los sistemas de regadío en al-Andalus, apunta dos creaciones diferenciadas: el sistema sirio (Valencia, Castellón y Gandía) caracterizado por la distribución proporcional del agua; y el sistema yemenita, típico de las pequeñas huertas (Alicante, Elche y Novelda) basado en unidades de 
medida de tiempo fijo, y asociado con la venta de agua. Ambos, también corresponden a dos sistemas opuestos de posesión de la tierra: uno en el cual los derechos de agua son inseparables de la tierra y otro en el cual el derecho de agua puede ser vendido separado de la tierra. Para Glick, los cristianos heredaron el sistema árabe y lo mantuvieron y cuidaron. Nos remite a un documento clave, el de la "Distribución de las aguas en 1244» (Archivos Municipales de Gandía), donde se solicita información consuetudinaria a un grupo de musulmanes para saber de qué manera se distribuían las aguas para seguir haciéndolo así, como en el "temps de moros» o "de sarrahins», expresiones estas que se utilizaron como tradición legal en los documentos postislámicos.

La obra de Glick es, por lo tanto, obra de consulta imprescindible para quien quiera entrar en la sociedad valenciana de la Edad Media y, mucho más, para quien quiera saber sobre el aprovechamiento del agua para regadío. Además, la lectura se hace amena y agradable. 